\title{
Homens autores de violência contra mulheres: políticas públicas, desafios e intervenções possíveis na América Latina e Portugal
}

\author{
Men perpetrators of violence against women: public policy \\ challenges and possible interventions in Latin America and Portugal
}

http://dx.doi.org/10.5007/2178-4582.2017v51n1p174

\author{
Maria Juracy F. Toneli, Adriano Beiras e Juliana Ried \\ Universidade Federal de Santa Catarina, Florianópolis/SC, Brasil
}

\begin{abstract}
A partir de pesquisas exploratórias desenvolvidas na América Latina e Portugal que mapearam programas para homens autores de violência contra mulheres, este artigo problematiza como estes homens têm sido visibilizados pelas políticas públicas. Metodologicamente, foram realizadas visitas a cada um dos serviços, observação das rotinas e o acesso aos materiais por eles produzidos, bem como entrevistas com seus coordenadores. São iniciativas de entidades não governamentais, majoritariamente, muito embora, tenha crescido no Brasil intervenções governamentais depois da criação da Lei Maria da Penha. Em Portugal, dos quatro programas visitados, três deles estão vinculados a universidades e outro a um hospital. Ao esboçar alguns dos enfrentamentos para atender a demanda masculina, o êxito dos programas precisa ser salientado, ao propor atendimentos educativos reflexivos e/ou terapêuticos. Através da elaboração e fortalecimento de políticas públicas e de intervenções que deem visibilidade aos homens autores de violência amplia-se a possibilidade de promover mudanças neste cenário.
\end{abstract}

Palavras chaves: violência de gênero; programas de atendimento a homens; políticas públicas.
From exploratory researches done in Latin America and Portugal that have mapped programs for men perpetrators of violence against women, this paper intends to problematize how these men have been regarded by public policies. As to the methodology, visits were made to each program, along with routine observations and access to the materials produced by them, as well as coordinators interviews. The majority of initiatives have been developed by NGOs, however, in Brazil, governmental interventions are growing since the Maria da Penha Law was enacted. In Portugal, four programs were visited, three of which were linked to universities and the other to a hospital. While some difficulties are identified to give support to the male demand, it is important to emphasize the success of programs that propose educational and reflexive interventions. Thus, through reinforcement of public policies and interventions to give visibility for men perpetrators of violence, the possibility to promote changes in this context can be widely expanded.

Keywords: gender violence; intervention programs for men; public policies.

\section{Introdução}

Este texto baseia-se em pesquisas exploratórias desenvolvidas respectivamente, na América Latina ${ }^{1}$ e em Portugal que buscaram investigar e mapear programas de atendimento a homens que cometeram violência contra mulheres. Foram realizadas visitas a cada um dos serviços, possibilitando a observação das rotinas e o acesso aos materiais por eles produzidos, bem como entrevistas com seus coordenadores. Toma por base de discussão também, 
um mapeamento realizado posteriormente, em 2013, no contexto brasileiro sobre este tema, pelo Instituto Noos, do Rio de Janeiro. Estas investigações asseveraram o interesse de problematizar as políticas públicas no tocante aos homens autores de violência. Estas políticas são compreendidas como ações, iniciativas, serviços e/ou programas que venham a ser desenvolvidos e implementados pelo Estado para atender demandas públicas. Neste tema tratam-se de políticas públicas que se articulam com demandas da saúde, assistência social e segurança pública. Em que medida estas ações têm tido visibilidade no contexto das ações públicas governamentais e não governamentais? Há políticas públicas que direcionem ações e propostas de intervenção? Os programas mapeados em certa medida trouxeram uma perspectiva positiva das propostas de intervenção que desenvolvem. No entanto, alguns dos enfrentamentos e desafios enunciam aspectos que políticas públicas, quando devidamente articuladas, poderiam suprir.

As pesquisas que embasam a discussão neste trabalho foram desenvolvidas em diferentes momentos, sendo primeiramente desenvolvida a pesquisa na América Latina ${ }^{2}$ pelo núcleo de pesquisa Margens - Modos de vida, Família e Relações de Gênero, do Departamento de Psicologia da Universidade Federal de Santa Catarina- UFSC, em parceria com grupos de pesquisa ${ }^{3}$ da Universidade Federal do Espírito Santo, da Universidade Federal de Pernambuco e da ONG Instituto PAPAI (Recife). Posteriormente, o núcleo Margens - UFSC deu continuidade à proposta em Portugal ${ }^{4}$, no intento de analisar comparativamente os serviços e/ou programas mapeados na América Latina e neste país europeu, que por sua vez, além de guardar algumas semelhanças com as tradições culturais brasileiras também vem desenvolvendo iniciativas dessa natureza.

$\mathrm{Na}$ América Latina foram mapeados serviços e/ou programas em seis países (Brasil, Argentina, Peru, México, Nicarágua e Honduras) que atendem a homens autores de violência contra mulheres. A escolha pelos países latinos exceto o Brasil) deveu-se ao fato de neles já haver uma tradição consolidada desse tipo de trabalho, em função da problemática ser considerada de alta importância social e da existência de financiamento internacional destinado às organizações não-governamentais que ali se instalaram (TONELI; LAGO; BEIRAS; CLÍMACO, 2010). Convém mencionar, que no Brasil, embora a

\footnotetext{
2 Relatório Final da pesquisa intitulada: "Violência Sexual e Saúde Mental: análise dos programas de atendimento a homens autores de violência sexual", disponível em: http://www.endvawnow.org/uploads/browser/files/ Brazil_sexual\%20violence\%20and\%20mental\%20health.pdf

3 Grupo de pesquisa Representações, Práticas Socioculturais e Processos de Exclusão do Departamento de Psicologia da Universidade Federal do Espírito Santo, o Núcleo de Pesquisa em Gênero e Masculinidades (GEMA) do Departamento de Psicologia da Universidade Federal de Pernambuco.

4

Pesquisa intitulada: "Estreitando o diálogo entre América Latina e Portugal: análise dos programas de atendimento a homens autores de violência contra mulheres", financiada pelo CNPq por meio de Bolsa PQ, que por sua vez, teceu uma análise comparativa entre os serviços/programas mapeados na América Latina e Portugal.
} 
proposta de atender homens ainda fosse incipiente, tinha como referência algumas práticas já consolidadas nos outros países latino americanos mapeados.

A grande maioria dos programas visitados nos países latinos e no país europeu trabalha com módulos sucessivos de atividades que podem atingir até dois anos sequenciais, predominando intervenções educativas e terapêuticas grupais. Muito embora, em Portugal as intervenções individuais predominem, uma vez que um dos enfrentamentos é a deserção dos atendimentos em grupo. A despeito dos diferentes aportes teórico-metodológicos e da diversidade de formação dos profissionais que trabalham com os usuários, foi possível identificar estratégias comuns que tem como ponto de partida o entendimento sobre o que é violência e que os sujeitos possam se reconhecer como autores de ações violentas.

No Brasil, embora se reconheça a gravidade da situação, no que diz respeito a violência contra a mulher, foi nos últimos dez anos, com a aprovação da Lei Maria da Penha (Lei 11.340/2006), que se conquistou legitimidade suficiente para que essa modalidade de atendimento seja prevista e, portanto, incentivada ${ }^{5}$. Apesar de já ter passado dez anos da criação da Lei Maria da Penha, que indica também o trabalho com autores de violência, políticas neste setor ainda são muito frágeis no país, tornando relevante a necessidade de maiores discussões, estudos, ações e intervenções concretas nacionalmente, como propomos neste artigo. Corroboram Lima e Buchele (2011) que a promulgação desta lei foi a grande responsável pela modificação do cenário da violência contra a mulher, enfatizando os Artigos 35 e 45. Conforme a Lei Maria da Penha, no Artigo 35, indica a possibilidade de criar e promover "centros de educação e de reabilitação para agressores" e no Artigo 45 indica a possibilidade do comparecimento obrigatório do agressor a "programas de recuperação e reeducação" (BRASIL, 2006). Todavia, programas ou iniciativas voltadas ao autor de violência contra a mulher ainda apresentam menor enfoque na prática, embora sejam crescentes. Apontam os/as autores/as:

Apesar do crescente interesse da literatura científica e da intervenção em saúde com o envolvimento dos homens, em especial, no campo dos direitos sexuais e reprodutivos, comparativamente, reflexões e intervenções com homens autores de violência contra a mulher têm recebido bem menos atenção de órgãos governamentais, não-governamentais e pela academia. (LIMA; BUCHELE; CLÍMACO, 2008, p. 69)

5 Lei 11340/2006 - por exemplo em seu artigo 30: Art. 30. Compete à equipe de atendimento multidisciplinar, entre outras atribuições que lhe forem reservadas pela legislação local, fornecer subsídios por escrito ao juiz, ao Ministério Público e à Defensoria Pública, mediante laudos ou verbalmente em audiência, e desenvolver trabalhos de orientação, encaminhamento, prevenção e outras medidas, voltados para a ofendida, o agressor e os familiares, com especial atenção às crianças e aos adolescentes. 
O mapeamento exploratório, porém, não exaustivo, realizado em 2013/2014 pelo Instituto Noos $^{6}$, indica o crescimento de programas e iniciativas governamentais por vezes pontuais no Brasil, ainda que de forma incipiente se pensarmos no tamanho do país e da necessidade de ações mais efetivas. Neste estudo se percebe uma diferença em relação ao mapeamento latino americano mencionado anteriormente e indica-se a necessidade de uma política nacional neste tema para evitar que programas sejam fechados por faltas de incentivos financeiros, sustentabilidade e políticas públicas específicas.

Nossa proposta neste texto não está em aprofundar ou descrever resultados das pesquisas mencionadas e sim problematizar algumas questões principais comuns a estes relatórios de pesquisa e mapeamentos, em especial no que tange às políticas públicas, leis e desafios de intervenção neste setor e temática.

\section{Caminhos teóricos e conceituais para pensar a prática}

Nas últimas décadas o tema da violência tornou-se um vasto campo de estudos de diversas disciplinas, sendo abordado por diferentes vertentes analíticas. Chauí (1985) elaborou um conceito de violência, também apresentado por Araújo (2002), que a encara não como uma violação de normas, regras e leis, mas como “[...] conversão de uma diferença e de uma assimetria numa relação hierárquica de desigualdade, com fins de dominação, de exploração e opressão [...] ação que trata um ser humano não como sujeito, mas como coisa" (CHAUÍ, 1985, p. 4). É possível, portanto, pensar a violência de gênero a partir desse entendimento, que inclui a ideia de assimetria e desigualdade, em uma relação que "coisifica" o outro.

De acordo com Ribeiro (2004), pode-se considerar violento aquilo que extrapola os limites de cada um/a, invadindo e desestruturando sua subjetividade. Quando se trata da violência doméstica, isso significa que essa invasão é vivenciada, via de regra, com alguém que tem um lugar de referência para aquele/a que sofre a situação, o que faz com que no desenrolar desse processo se misturem sentimentos contraditórios de amor e ódio. Afinal, a pessoa amada é a mesma que comete a violência, incitando essa dualidade emocional. A própria Lei Maria da Penha traz em seu texto muitas contribuições do que foi elaborado academicamente a esse respeito incluindo, por exemplo, os conceitos de violência doméstica e de sofrimento psicológico. Conforme explicita em seu Artigo $5^{\circ}$ que "configura violência doméstica e familiar contra a mulher qualquer ação ou omissão baseada no

6 Para maiores informações sobre este mapeamento, ver link: http://noos.org.br/portal/wp-content/uploads/2015/04/Relatorio-Mapeamento-SHAV_site.pdf 
gênero que lhe cause morte, lesão, sofrimento físico, sexual ou psicológico e dano moral ou patrimonial" (BRASIL, 2006).

Outro enfoque importante é a compreensão da violência como uma questão de saúde pública e que Manita (2005) salienta ser um dos problemas mais sérios enfrentados pelas sociedades ocidentais. Segundo a Organização Mundial de Saúde (OMS) a violência caracteriza-se

como o uso intencional da força física ou do poder, real ou
em ameaça, contra si próprio, contra outra pessoa ou contra
um grupo ou uma comunidade, que resulte ou tenha grande
possibilidade de resultar em lesão, morte, dano psicológico,
deficiência de desenvolvimento ou privação. (KRUG;
DAHLBERG; MERCY; ZWY; LOZANO, 2002, p. 5)

Segundo os Princípios e Diretrizes da Política Nacional de Atenção Integral à Saúde da Mulher, com base na Organização Panamericana de Saúde (OPAS), "[...] a literatura vem demonstrando que determinados comportamentos, tanto dos homens quanto das mulheres, baseados nos padrões hegemônicos de masculinidade e feminilidade, são produtores de sofrimento, adoecimento e morte" (BRASIL, 2004a, p. 16). Pode-se dizer, portanto, que uma das estratégias de enfrentamento é a construção e visibilização de outras masculinidades e feminilidades, que possam integrar aspectos relacionadas a equidade de gênero e diversidade. Propostas que promovam problematizações e desconstruções de subjetividades, trazendo novos horizontes relacionais e também culturais (ANTEZANA, 2012; BEIRAS, 2012, BEIRAS; CANTERA; ALENCAR-RODRIGUES, 2015; BEIRAS, BRONZ, 2016).

Dessa maneira, destaca-se a visão da violência como um problema de saúde pública e, mais especificamente, de saúde mental, compreendida como um processo complexo de construção cotidiana, individual e coletiva do ser humano em relação aos seus sentimentos, seu corpo, sua sexualidade e seu meio. Medrado e Mello (2008) assinalam que é neste contexto mais amplo que se busca a relação entre violência e saúde mental. Mencionam ainda, que conforme estudo da OPAS a pessoa que vive em um contexto violento, e/ou que esteja vulnerável à violência, também se encontra em maior risco de sofrer agravos à saúde. Conforme corroboram Heise, Ellsberg e Gottemoeller (1999) a violência contra as mulheres está relacionada a graves problemas de saúde, imediata e a longo prazo. No tocante aos agravos à saúde mental elencam: estresse pós-traumático, depressão, ansiedade, fobias/pânico, desordens alimentares, disfunção sexual, baixa autoestima e abuso de substâncias (álcool e outras drogas). Assim, não se pode pensar/atuar nesta construção cotidiana 
e nas suas implicações para a saúde mental e a violência contra a mulher, sem envolver os homens, como aponta Heleieth Saffioti (2004):

\begin{abstract}
As pessoas envolvidas na relação violenta devem ter o desejo de mudar. É por esta razão que não se acredita numa mudança radical de uma relação violenta, quando se trabalha exclusivamente com a vítima. Sofrendo esta, algumas mudanças, enquanto a outra parte permanece o que sempre foi, mantendo seus habitus, a relação pode inclusive, tornarse ainda mais violenta. Todos percebem que a vítima precisa de ajuda, mas poucos veem esta necessidade no agressor. As duas partes precisam de auxílio para promover uma verdadeira transformação da relação violenta. (SAFFIOTI, 2004, p. 68)
\end{abstract}

Segundo Dantas-Berger e Giffin (2005), no caso da violência contra as mulheres, a maioria dos dados brasileiros aponta para a maior ocorrência (ou visibilidade) das violências físicas, seguidas pelas violências psicológicas (ameaça, difamação, injúria), sendo que "A violência sexual, especialmente a coerção e/ou violência sexual praticada por parceiro íntimo no âmbito privado, está pouco evidenciada ou inexistente nas estatísticas disponíveis" (DANTAS-BERGER; GIFFIN, 2005, p. 419-420).

\title{
Por que trabalhar com homens autores de violência?
}

A ideia de atender homens autores de violência contra mulheres baseia-se na aposta de que o sujeito possa reconhecer sua dificuldade e criar instrumentos para lidar com ela. Além disso, baseia-se na perspectiva de que a violência e o gênero são relacionais e é necessário exercer atuações mais amplas com todas as partes envolvidas, rompendo ações dicotômica e lineares (LIMA; BUCHELE, 2011; BEIRAS, 2012, BEIRAS et al., 2012). Busca-se o engajamento da população masculina na promoção da equidade de gênero e nas ações pelo fim da violência de homens contra as mulheres, aliançados com pressupostos feministas (BEIRAS; CANTERA, 2014, BEIRAS; BRONZ, 2016).

Trabalhar com pessoas envolvidas em situação de violência, principalmente ao se abordar a perspectiva do autor de agressão, exige do profissional uma investigação atenta quanto à intencionalidade e à motivação do ato praticado, quanto ao dano consequente do ato, quanto à percepção que o autor tem do resultado dessa violência, e se de fato, o autor vê sua ação como violenta (LIMA, 2004). Uma compreensão adequada da situação de violência deve levar em conta os significados em torno dessa temática que são prevalentes no grupo cultural de referência dos envolvidos (BEIRAS; CANTERA; ALENCAR-RODRIGUES, 2015). É pertinente também, que as 
pessoas envolvidas em situação de violência não sejam fixadas em lugares de "vítima" ou "agressor", e, dessa maneira, se crie a chance para que a voz de cada sujeito seja ouvida, bem como os descolamentos que essa postura pode proporcionar. Lima e Buchele (2011) assinalam que uma compreensão da dimensão relacional de gênero possibilita que a situação de violência não se reduza "a expressões individuais de um homem, como algoz e de uma mulher, como vítima passiva" (LIMA; BUCHELE, 2011, p. 733).

\section{O contexto brasileiro e o português - ações, leis e políticas}

Uma vez que há uma proximidade histórica e cultural entre Brasil e Portugal, considerou-se pertinente atentar às ações, leis e políticas que estes países vêm implementando. No Brasil, foi a partir da década de 80 que a questão da violência doméstica e conjugal passou a ganhar visibilidade por meio da luta de mulheres e suas mobilizações de rua e protestos contra a violência machista. Juntamente à articulação dos movimentos feministas da época que trouxeram à tona a necessidade e urgência de investimentos do Estado em políticas de proteção às mulheres vítimas de violência. (BRAZÃO; OLIVEIRA, 2010). Foi então, que vieram a ser aprovadas e implementadas leis mais explícitas relacionadas à violência contra as mulheres e a estruturar abrigos $^{7}$ e delegacias especializadas no atendimento de mulheres vítimas de violência.

Um dos intensos debates dessa área centrava-se na Lei dos Juizados Especiais Criminais (Lei 9.099/95), que julga e processa infrações de "menor potencial ofensivo", na qual a violência contra a mulher geralmente era enquadrada (excluindo homicídios e lesões corporais graves). A possibilidade dos homens autores de violência julgados pela Lei 9.099/95 terem sua pena convertida em penas alternativas e, principalmente, a maneira como estava ocorrendo (geralmente sob a forma de pagamento de cestas básicas), era criticada pela maioria dos setores que lidavam com a violência contra a mulher. Esta legislação não especificava em nenhum lugar que tipo de pena alternativa devia ser indicada, e por se acreditar que a prisão não seria a melhor solução para boa parte dos casos, o atendimento psicossocial desses homens passou a ser considerado uma alternativa viável e positiva.

\footnotetext{
$7 \quad$ Os abrigos e as Delegacias Especializadas de Atendimento à Mulher constituíram as principais políticas de enfrentamento da violência contra as mulheres até 2003. Com a promulgação da Lei Maria da Penha foram criadas as casas-abrigo e as casas de acolhimento provisório, especificadas nas Diretrizes Nacionais Para o Abrigamento de Mulheres em Situação de Risco e de Violência. Disponível em: http://www.spm.gov.br/sobre/publicacoes/publicacoes/2011/ abrigamento

8 Lei 9.099/95. Dispõe sobre os Juizados Especiais Cíveis e Criminais e dá outras providências. Disponível em $<\underline{\text { http://www.tjdft.jus.br/institucional/2a-vice-presidencia/relatorios/nupemec/relatorio-semestral-nupemec-10-2013/ }}$ anexo-08-legislacao-nupemec/Lei $\% 209.099 \% 20-\% 2026.09 .1995 \% 20-\% 20 J u i z a d o s \% 20$ Especiais $\% 20$ Civeis $\% 20 \mathrm{e} \% 20$ Criminais.pdf>
} 
A partir dessas críticas à Lei 9.099/95, o Poder Executivo submeteu, em novembro de 2004, à apreciação do Congresso Nacional o Projeto de Lei n. ${ }^{\circ}$ $4.559 / 04$. Este projeto cria mecanismos para coibir a violência doméstica e familiar contra a mulher, nos termos do $\S 80$ do art. 226 da Constituição Federal e dos tratados internacionais ratificados pela República Federativa do Brasil, como Convenção sobre a Eliminação de Todas as Formas de Discriminação contra a Mulher - Cedaw (1981), a Convenção Interamericana para Prevenir, Punir e Erradicar a Violência Contra a Mulher - Convenção de Belém do Pará (1994), entre outras não menos importantes.

Cria os Juizados de Violência Doméstica e Familiar contra a Mulher e estabelece as medidas para a prevenção, assistência e proteção às mulheres em situação de violência. Nas disposições finais (Título V), artigo 39, o projeto de lei destacava que o Estado Brasileiro deveria criar e promover, entre outros, centros de educação e de reabilitação para os acusados de violência doméstica e familiar. Além disso, em seu artigo 40, o projeto dizia claramente que "compete à União, ao Distrito Federal, aos Estados e aos Municípios promoverem a adaptação de seus órgãos e de seus programas às diretrizes e aos princípios estabelecidos nesta Lei” (BRASIL, 2004b).

Finalmente, em agosto de 2006, foi sancionada a Lei 11.340/2006, que popularmente passou a ser conhecida como Lei Maria da Penha. Este nome é uma homenagem a Maria da Penha Maia, que foi vítima de agressão de seu marido por seis meses, enfrentando por duas vezes tentativas de homicídio, como amplamente divulgado. Seu marido foi punido somente depois de 19 anos de julgamento. Essa lei altera o Código Penal Brasileiro triplicando a pena para agressões domésticas contra mulheres e, em consequência, aumentando os mecanismos de proteção às vítimas. Possibilita que agressores sejam presos em flagrante e extingue penas alternativas. Medidas preventivas para proteger a mulher em situação de agressão também estão previstas na lei, tais como: a saída do agressor da casa, a proteção dos filhos e o direito da mulher de reaver bens e também de cancelar procurações feitas no nome do agressor. Outro avanço é que a violência psicológica passa a ser considerada juridicamente como violência doméstica e emocional'.

Com a "Lei Maria da Penha", o Brasil passou a ser o $18^{\circ}$ país da América Latina a possuir em sua legislação uma lei específica para casos relacionados à violência doméstica e contra as mulheres, definindo as formas de violência

9 Art. 7ำ - II - a violência psicológica, entendida como qualquer conduta que lhe cause dano emocional e diminuição da auto-estima ou que lhe prejudique e perturbe o pleno desenvolvimento ou que vise degradar ou controlar suas ações, comportamentos, crenças e decisões, mediante ameaça, constrangimento, humilhação, manipulação, isolamento, vigilância constante, perseguição contumaz, insulto, chantagem, ridicularização, exploração e limitação do direito de ir e vir ou qualquer outro meio que lhe cause prejuízo à saúde psicológica e à autodeterminação. 
vividas por mulheres no cotidiano, tais como: física, psicológica, sexual, patrimonial e moral ${ }^{10}$.

Além da legislação específica, o Brasil conta, desde 2007, com o Pacto Nacional pelo Enfrentamento à Violência contra as Mulheres (grifo nosso), que consiste num acordo federativo entre o governo federal, os governos dos estados e dos municípios para o planejamento de ações que visem à consolidação da Política Nacional de Enfrentamento à Violência contra as Mulheres (BRASIL, 2011), por sua vez, viabilizada por meio da implementação de políticas públicas integradas em todo o território nacional. A referida Política Nacional foi publicada em 2011 e seu texto, além de contextualizar a violência contra as mulheres no Brasil, define a violência e seu enfrentamento, conceitua a rede de atendimento, estabelece princípios, diretrizes, objetivos, ações e prioridades. A Secretaria de Políticas para as Mulheres, criada em 2003 no país, cumpre papel fundamental na articulação dos documentos, leis e ações que compõem esse conjunto. A Central de Atendimento à Mulher, por meio do Disque 180, promove a possibilidade de denúncias, para além do atendimento usual nas Delegacias Especializadas, disponibilizando outra iniciativa importante nessa rede de enfrentamento.

Em Portugal, a questão da violência contra as mulheres tem merecido nos últimos anos uma atenção muito especial por parte do governo português, bem como por organismos internacionais, como é o caso do Conselho da Europa ou das Nações Unidas. Ações de intervenção de enfrentamento a violência, tanto nos campos social e acadêmico como no jurídico, encontraram solo fértil em Portugal desde a década de 1970.

Além de toda a tradição e as questões próprias da cultura portuguesa, é pertinente resgatar o fato de que Portugal esteve sob regime ditatorial por 42 anos (1932-1974) e até 1975, o Código Penal Português, em seu o artigo 372, considerava possível que o homem exercesse violência contra sua mulher, inclusive direito de matá-la. Este foi revogado em maio do referido ano pelo Decreto de Lei $262 / 75^{11}$. Neste sentido, Guimarães (1986) ao trazer uma análise esquemática da mulher portuguesa na legislação civil em diferentes períodos históricos, explicita o lugar de submissão, sob risco de violência e obediência ao marido. Deste modo, perpetuou-se historicamente e socialmente a ideia de que o homem, reconhecido legal e socialmente como o chefe da família, teria legitimidade para exercer violência sobre a mulher no contexto doméstico. Isso acabou por se tornar um problema social, uma vez que os

10 Em 09 de março de 2015, foi sancionada pela Presidência da República a Lei 13.104/2015, que qualifica o feminicídio no rol de crimes hediondos. Embora não inclua, travestis e mulheres transexuais, a lei é considerada um avanço no âmbito do enfrentamento das violências contra as mulheres. Disponível em <http://www.planalto.gov.br/ ccivil_03/_Ato2015-2018/2015/Lei/L13104.htm>.

11 Decreto de Lei 262/75, disponível em: https://dre.pt/application/file/336043 
arranjos familiares sofreram transformações significativas ao longo desses anos, o que tornou ainda mais visível a problemática da violência conjugal. E foi a partir da Constituição de $1976^{12}$ que então, tornou-se prevista a plena igualdade entre homens e mulheres, estendendo-se no tratamento no interior da família (ALVIM, 2006).

Foi com a criação do I Plano Nacional contra a Violência Doméstica, em 1999, que houve uma preocupação quanto à integração social dos autores de violência, na medida em que se considerava a possibilidade destes (re) aprenderem comportamentos destituídos de violência. Esta preocupação continuou e continua tendo espaço na realidade nacional, tanto do ponto de vista preventivo como o de intervenção junto a agressores em meio comunitário. As políticas portuguesas no combate a violência contra a mulher vem se consolidando com os subsequentes Planos Nacionais Contra a Violência Doméstica (PNCVD).

Atualmente está em vigor em Portugal o V Plano Nacional de Prevenção e Combate à Violência Doméstica e de Género (grifo nosso) (PNPCVDG), (2014-2017), que ressalta o compromisso assumido pelo país junto a instâncias internacionais como a Organização das Nações Unidas e o Conselho da Europa, enfatizando que foi o primeiro país da União Europeia a ratificar o instrumento internacional, Combate à Violência contra as Mulheres e a Violência Doméstica (Convenção de Istambul), em 5 de fevereiro de 2013. No documento se enfatiza que:

O V PNPCVDG procura, assim, delinear estratégias no sentido da proteção das vítimas, da intervenção junto de agressores (as), do aprofundamento do conhecimento dos fenômenos associados, da prevenção dos mesmos, da qualificação dos(as) profissionais envolvidos(as) e do reforço da rede de estruturas de apoio e de atendimento às vítimas existente no país. (PORTUGAL, 2013, p. 7017)

Destaca medidas já preconizadas nos anteriores, que hoje se consolidam com o reforço do papel das organizações da sociedade civil na promoção da igualdade de gênero e no combate a violência doméstica, mencionando o apoio aos inúmeros projetos que incluem ações de sensibilização, apoio a vítimas e intervenção com agressores. No entanto, alarga o espectro dos planos anteriores, de acordo com a Convenção de Istambul, ao incluir outras formas de violência de gênero como mutilação genital e agressões sexuais, para além da violência doméstica. 
Importante se faz destacar, portanto, que se em Portugal, tanto as investigações como as intervenções se concentraram no âmbito da violência doméstica e não especificamente na violência contra as mulheres, apesar destas se destacarem como as "principais vítimas", o espectro se alargou e, hoje, novas frentes de ação se abrem nesse campo. A violência vivenciada por muitas mulheres nos seus próprios lares conta com a denúncia e o apoio de certas Organizações Não Governamentais. Entre estas se destacam a Comissão para a Igualdade e para os Direitos das Mulheres, a Associação Portuguesa de Apoio à Vítima (APAV) e a Associação de Mulheres contra a Violência.

\section{Caminhos metodológicos - o material analisado}

Nas duas pesquisas mencionadas (América Latina e Portugal) o campo implicou na realização de entrevistas semi-estruturadas com os gestores dos referidos programas e/ou serviços, visitas às instituições, análise de material programático e, quando possível, observações participantes dos grupos de homens. As entrevistas aos coordenadores e /ou gestores foram gravadas e nortearam-se por um roteiro semi-estruturado com dezoito perguntas ou temas que incidiam sobre suas metodologias de intervenção, formas de encaminhamento, constituição da equipe, dificuldades e facilidades encontradas para a obtenção dos objetivos, bem como formas de financiamento.

Desse modo, se viabilizou a investigação das propostas de ação voltadas ao atendimento a homens autores de violência contra mulheres na América Latina e em Portugal. Posteriormente, foi realizado pelo Instituto Noos do Rio de Janeiro, em 2013/2014, um mapeamento de iniciativa no Brasil através de questionários com perguntas abertas, semi abertas e fechadas. Como forma de atualizar estas pesquisas anteriores com grupos considerados pioneiros e considerando nossas parcerias de pesquisa com esta ONG, incluímos neste texto reflexões deste mapeamento, de forma a produzir atualizações e reflexões sobre o contexto estudado. É a partir da análise destes estudos que se contextualiza a problematização das políticas públicas relativas a homens autores de violência contra as mulheres e a violência de gênero no presente texto.

\section{Desafios, questionamentos e reflexões sobre as políticas públicas}

Nossa proposta neste texto não está em aprofundar ou descrever resultados das pesquisas mencionadas e sim problematizar algumas questões principais comuns a estes relatórios de pesquisa e mapeamentos, em especial no que tange às políticas públicas, leis e desafios de intervenção neste setor e temática. A partir dos programas mapeados na América Latina e em Portugal foi possível perceber que as políticas públicas privilegiam principalmente o 
atendimento a mulheres vítimas de violência, muito embora, haja legislações tanto no Brasil, por exemplo, com a Lei Maria da Penha, como em Portugal com o V Plano de Prevenção e Combate à Violência Doméstica e de Género (2013), que incluem ou sinalizam intervenções junto aos homens autores de violência contra mulheres.

Em se tratando do Brasil, na Lei Maria da Penha, apresenta entre as medidas preventivas, a promoção de estudos e pesquisas com a perspectiva de gênero relacionadas à violência doméstica e familiar contra a mulher, bem como a celebração de convênios e parcerias com o objetivo de implementação de programas de erradicação da violência doméstica e familiar contra as mulheres. Outro aspecto sancionado nesta lei, que merece especial atenção, está na recomendação de que o juiz deve determinar o comparecimento obrigatório do agressor a programas de recuperação e reeducação. A este respeito, convém salientar, que está em tramitação o Projeto Lei do Senado ${ }^{\circ}$ 9 de $2016^{13}$, já aprovado pelo Plenário do Senado, que altera a lei supracitada, em seu Artigo 23, para estabelecer a medida protetiva de frequência a centro de educação e reabilitação do agressor.

Em Portugal já no IV Plano Nacional, as políticas públicas se mostram bem estruturadas para prevenir e intervir junto aos sujeitos que cometem violência, sendo crescente a tendência à implementação de programas de prevenção da reincidência em agressores. Consta do texto, que "é insuficiente trabalhar apenas com as vítimas; a intervenção junto de agressores contribui para a alteração dos estereótipos e das crenças socialmente enraizados" (PORTUGAL, 2010, p. 5570), e que por sua vez, propiciam as condições geradoras e a aceitação da violência doméstica. Da mesma forma, os sujeitos chegam aos programas e/ou serviços, encaminhados pelo judiciário ou, em menor incidência, espontaneamente.

Nesta direção, políticas públicas para que sejam efetivas, precisam consolidar o funcionamento de uma rede bem articulada implicada com a demanda da violência e atenta à proteção das vítimas, ações de combate a violência, à promoção e adoção de medidas desta rede em prol da prevenção às situações de risco e da intervenção junto aos homens autores de violência. Convém salientar que profissionais qualificados e que possam aprimorar sua prática no tema da violência são imprescindíveis, pois, são justamente estes profissionais que colocam a política em prática junto à demanda em questão, seja na intervenção junto à sociedade civil, ONGs, ou organizações governamentais. 
Universidades também podem se engajar no combate à violência através de pesquisas e até mesmo propostas de intervenção, como mostraram três dos quatro programas/serviços contatados em Portugal. Estes, por sua vez, se vinculavam à Universidade do Porto ("Programa de intervenção com agressores" - Gabinete de estudo e atendimento a vítimas (GEAV)/ Centro de Ciências do Comportamento Desviante); à Universidade do Minho ("Programa com agressores conjugais" - Unidade de consulta em psicologia da justiça (UCPG); e à Universidade Lusófona de Lisboa ("Programa de atendimento a homens agressores"). Sendo que, o quarto serviço se vinculava ao Hospital Sobral Cid ("Serviço de Violência Familiar"), em Coimbra.

Conforme Manita (2005), a intervenção e investigação sobre os agressores de violência conjugal são escassas em Portugal. Através da sistematização preliminar de pesquisa realizada, destacam-se a Universidade do Porto e a Universidade do Minho como instituições que vem atuando com agressores no contexto de violência doméstica (MANITA, 2005, p. 50)

Convém mencionar que no Brasil, universidades também estão engajadas em pesquisas no enfoque do homem autor de violência (a exemplo, UFSC, UEPG, UFMG, UFPR, USP, entre outras), desenvolvendo diferentes atividades voltadas para investigações relacionadas à intervenção e ensino, direcionadas à equidade de gênero em torno de diversas problemáticas: saúde e direitos sexuais e reprodutivos, violência e discriminações de gênero, paternidades e masculinidades, processos de exclusão/inclusão, bem como ações articuladas com instituições de diversos estados brasileiros que integram a Rede de Homens pela Equidade de Gênero - RHEG. É através do apoio de entidades como Secretaria Especial de Políticas para as Mulheres, Ministério da Saúde, $\mathrm{CNPq}$, entre outras organizações, que as instituições e grupos de pesquisa viabilizam suas ações. Ainda assim, há necessidade de melhor articulação em rede das experiências nacionais e internacionais, diretrizes, metodologias e articulação com outros serviços de enfrentamento da violência. Nota-se barreiras e desafios institucionais, além de preconceitos com este tipo de trabalho que precisam ser explorados. Além disso, percebe-se a necessidade de atuações que desenvolvam um olhar feminista e de gênero, atento a estudos de masculinidades e violências sem cair em psicologização ou patologização, perspectivas que reduzem a complexidade da problemática (ANTEZANA, 2012; BEIRAS, 2012; BEIRAS; CANTERA, 2014).

Ao recuperar a análise dos programas e/ou serviços mapeados na América Latina e em Portugal, convém mencionar que tanto em algumas organizações não governamentais, que predominam na América Latina no atendimento ao homem autor de violência, como nas universidades mencionadas em Portugal, um dos enfrentamentos é a carência de recursos financeiros para estruturar os 
programas e assegurar a equipe profissional. Este aspecto também sobressai no mapeamento realizado pela ONG do Rio de Janeiro, na medida em que se aponta que os recursos muitas vezes são pontuais, causando o fechamento de alguns programas depois de algum tempo por faltas de políticas e incentivos de permanência da ação. Como o Estado pode viabilizar e assegurar recursos a estes programas e /ou serviços? Como a rede profissional poderia mobilizar instituições parceiras? Será o estigma carregado pela demanda que ocasiona entraves para que cheguem os recursos? Estes questionamentos são suscitados, uma vez que já existem diretrizes que balizam o atendimento a homens que cometem violência contra mulheres. Onde estaria a lacuna da política para esta demanda? O estudo latino americano aponta que os programas pioneiros são majoritariamente de organizações não governamentais, com financiamentos internacionais e, em muitos casos, serviços que se mantém com profissionais atuando de forma voluntária, sem recursos.

Por fim, ainda que tenham sido mapeados programas e/ ou serviços que atendam a homens autores de violência, e tenham a sua eficácia e importância política, e que haja diretrizes para as situações de violência de gênero, em específico no que toca aos homens que cometem violência contra mulheres, ainda se faz necessário o fortalecimento das políticas públicas específicas e diretrizes nacionais que garantam maior visibilidade e viabilidade das propostas de intervenção, e sua importância no combate a violências contra mulheres. Faz-se necessário, para um combate eficaz, a intervenção relacional, que contemple tanto o autor quanto a vítima, ou seja, que homens também possam acessar os respectivos serviços e/ou programas de atendimento para lidar com a questão da violência. De forma a evitar reincidências do autor de violência, a partir da sua responsabilização e conscientização. O predomínio de intervenções em prol da vítima de violência acaba por suscitar a impressão de que propostas que vislumbrem a outra face da demanda ainda são marginais e por vezes mal entendidas como propostas relevantes e importantes para o campo na própria política de enfrentamento de violências.

Nessa direção, se faz necessário o engajamento da população masculina na promoção da equidade de gênero e nas ações pelo fim da violência de homens contra mulheres. Dessa maneira, a implementação de programas com os autores de violência contra mulheres têm se mostrado uma tendência, e estudiosos da área salientam a necessidade de atribuir a responsabilidade ao agressor (MANITA, 2005, ANTEZANA, 2012, ACOSTA, BRONZ, 2014; TURINETTO; VICENTE; 2008). Ainda assim, há dificuldades de definir o melhor local para estes serviços no contexto brasileiro. Há iniciativas em tribunais de justiça, central de penas e medidas alternativas, Centros de Referência Especializado de Assistência Social (CREAS), presídios, ONGS, entre outros. Isso ainda é um ponto importante para ser discutido. 
A proposta de intervenção com agressores visa contribuir para a alteração dos estereótipos, questões culturais e crenças socialmente enraizadas (BEIRAS; BRONZ, 2016; BEIRAS; CANTERA; ALENCAR-RODRIGUES, 2015; TURINETTO; VICENTE; 2008), além da crescente ideia de que o homem violento pode mudar as suas atitudes e aprender formas de relacionamento interpessoal não violentas. Um dos pontos centrais promovidos por estas intervenções é o rompimento do ciclo da violência e as condições geradoras da mesma.

O tema da violência, por si só carrega uma conotação negativa, e ao se falar em homens autores de violência contra mulheres, tal olhar se intensifica. Assim como quem foi vitimizado, o autor de violência como a outra parte da situação, também precisa ser visibilizado. Compreendemos que esta visibilidade não pode ser restrita à responsabilização, confundida com a criminalização desses sujeitos (BEIRAS; MORAES; ALENCAR-RODRIGUES; CANTERA, 2012). A violência contra a mulher configura uma problemática de ordem cultural e histórica, com suas raízes na ideologia sexista que ainda hoje marca as organizações societárias. Individualizá-la e/ou psicopatologizá-la não parece ser a estratégia mais consistente para seu enfrentamento.

\section{Considerações finais - a centralidade e necessidade de políticas públicas específicas}

Seja no viés educativo, reflexivo e/ou terapêutico é imprescindível que estes sujeitos envolvidos na situação de violência possam ser encaminhados para acompanhamento em propostas de intervenção (ANTEZANA, 2012; BOIRA SARTO, 2010, TURINETTO; VICENTE; 2008). Essa é uma das estratégias centrais para que se caminhe na direção de erradicar a violência ou a reincidência da situação violenta.

No entanto, é imprescindível que se concretize políticas públicas específicas e leis específicas de regulamentação e manutenção destes grupos atentas a pressupostos feministas (ACOSTA, BRONZ, 2014; BEIRAS; CANTERA 2014), problematizando a categoria homem e masculinidades (BANIN; BEIRAS, 2016). Também faz-se importante garantir o diálogo em rede, capacitação, estudo de metodologias e diretrizes nacionais mínimas, pesquisas, financiamento público e continuidade destes serviços. É necessário ampliar as discussões sobre estas intervenções nas ações de políticas públicas nacionais, de forma a fortalecer estas propostas de intervenção, ampliando também ações de prevenção, de forma que possamos combater de maneira mais eficaz a violência contra mulheres. 
Sugere-se atenção a perspectivas que contemplem a complexidade da temática, o olhar de gênero como operador analítico (ANTEZANA, 2012, BANIN; BEIRAS, 2016, BEIRAS; BRONZ, 2016), ampliando pesquisas neste campo, em aspectos teóricos e metodológicos assim como políticos e feministas neste setor. Também é recomenda-se atentar para a perspectiva que contemple o olhar dos direitos humanos e a problematização de aspectos sociais e culturais.

Além disso, faz-se necessário pensar o comportamento dos homens envolvidos com a situação de violência a partir de seus contextos de vida, experiências e narrativas pessoais, focalizando o processo de socialização que produz conexões entre masculinidades e violência (BEIRAS; CANTERA, 2012). Essa perspectiva traz a participação da família e da cultura na produção de homens violentos e inclui questões sobre a violência estrutural de gênero, como uma construção social que determina uma relação desigual e opressiva entre as pessoas. Greig (2001) salienta a necessidade de articular as discussões acerca da masculinidade, gênero e violência, a fim de visualizar de forma mais concreta o lugar e a responsabilidade dos homens na violência baseada no gênero. Nesta direção Manita (2005) corrobora que as questões de gênero e de poder são basilares na situação de violência doméstica e não podem ser esquecidas pelos programas.

Este texto procurou problematizar reflexões derivadas dos estudos e mapeamentos explicitados, porém, sabemos que há limitações referentes a necessidade de atualização constante da situação destes grupos, que mudam rapidamente devido a falta de ações concretas do governo e dificuldades de continuidades de alguns programas, como já apontado no mapeamento realizado no instituto Noos, citado anteriormente. Ao problematizar em que medida os homens autores de violência têm sido visibilizados nas/pelas políticas públicas, faz-se importante o seu fortalecimento para que gradativamente as vulnerabilidades enfrentadas pelos programas e/ou serviços de atendimento sejam superadas. A atualidade e urgência de atenção à temática da violência contra mulheres persiste nos contextos estudados. Medidas devem tornar possível promover a equidade de gênero nos atendimentos no enfrentamento da violência e que se crie estratégias para superar contextos econômicos e políticos adversos. Muitos desafios seguem adiante e precisam ser estudados dentro de sua complexidade, evitando atuações simplistas e 
reducionistas, incluindo todos os envolvidos/as na problemática, assim como os diferentes setores que podem atuar em ações eficazes neste campo e problemática social.

\section{Referências}

ACOSTA, F.; BRONZ, A. Desafios para o trabalho com homens em situação de violência com suas parceiras íntimas. In: BLAY, E. A. (Org.). Feminismos e masculinidades. Novos caminhos para enfrentar a violência contra a mulher. São Paulo: Cultura Acadêmica, 2014. p. 139-148.

ALVIM, F. Mulheres invisíveis: relatório da campanha acabar com a violência sobre as mulheres. Amnistia Internacional - Lisboa: AI Portugal, 2006. Disponível em: $<\underline{\mathrm{http}: / / w w w}$. amnistia-internacional.pt/dmdocuments/Relatorio_das_Mulheres.pdf $>$ Acesso em 30 de agosto 2016.

ANTEZANA, Á, P. Intervenção com homens que praticam violência contra seus cônjuges: reformulações teórico-conceituais para uma proposta de intervenção construtivista-narrativa com perspectiva de gênero. Nova Perspectiva Sistêmica, Rio de Janeiro, v. 21, n. 42, p. 9-27 2012. Disponível em: http://www.revistanps.com.br/index.php/nps/article/view/121/96 . Acesso em 30 de janeiro de 2017.

ARAÚJO, M. de F. Violência e abuso sexual na família, Psicologia em Estudo, Maringá, v, 7, n. 2, jul/dez, p. 3-11, 2002. Disponível em: <http://www.scielo.br/pdf/pe/v7n2/v7n2a02.pdf $>$ Acesso em 18 de outubro 2016.

BANIN, S. A.; BEIRAS, A. A categoria homem nas políticas públicas e leis brasileiras. Psicologia em Estudo, Maringá, v. 21, n. 3, p. 523-535, jul./set. 2016. Disponível em: <http:// periodicos.uem.br/ojs/index.php/PsicolEstud/article/view/32256/pdf > . Acesso em 04 de junho de 2017.

BEIRAS, A. La (de)construcción de subjetividades em um grupo terapêutico para hombres autores de violência em sus relaciones afectivas. 352p. Tese (Doutorado em Psicologia Social) - Departamento de Psicologia Social, Universitat Autónoma de Barcelona. Barcelona, 2012.

BEIRAS, A.; BRONZ, A.. Metodologia de grupos reflexivos de gênero. Rio de Janeiro: Instituto Noos, 2016. Disponível em http://noos.org.br/portal/editora/outras-publicacoes/. Acesso em 28 de janeiro de 2017.

BEIRAS, A.; CANTERA, L. M. Narrativas pessoais, construções de Masculinidades aportações para a atenção psicosocial a homens autores de violência. Psico, Porto Alegre, v. 43, n. 2, pp. 251-259, abr./jun. 2012. Disponível em: http://revistaseletronicas.pucrs.br/ojs/index. php/revistapsico/article/view/10023/8035. Acesso em 29 de janeiro de 2017.

BEIRAS, A.; CANTERA, L. M. Feminismo pós-estruturalista e masculinidades: contribuições para a intervenção com homens autores de violência contra mulheres. In: BLAY, E. A. (Org.). 
Feminismos e masculinidades: novos caminhos para enfrentar a violência contra a mulher. São Paulo: Cultura Acadêmica, 2014. p. 29-44.

BEIRAS, A.; CANTERA, L. M.; ALENCAR-RODRIGUES, R. de. I am a bull! The construction of masculinity in a group of men perpetrators of violence against women in Spain. Universitas Psychologica, Bogotá, v. 14, p. 1525-1538. 2015.

BEIRAS, A.; MORAES, M.; ALENCAR-RODRIGUES, R. de, CANTERA, L. M. Políticas e leis sobre violência de gênero - reflexões críticas. Psicololia \& Sociedade, Belo Horizonte, v. 24, n. 1, p. 36-45, abr. 2012. Disponível em: $<\underline{\text { http://dx.doi.org/10.1590/S0102- }}$ 71822012000100005> Acesso em 28 de maio 2016.

BOIRA SARTO, S. Homens maltratadores. Histórias de violencia masculina. Zaragoza: Prensas Universitarias de Zaragoza, 2010.

BRASIL. Secretaria de Atenção à Saúde. Departamento de Ações Programáticas Estratégicas. Política nacional de atenção integral à saúde da mulher: princípios e diretrizes. Brasília, DF: Ministério da Saúde, 2004a. Disponível em < $\underline{\text { http://bvsms.saude.gov.br/bvs/publicacoes/ }}$ politica_nac_atencao_mulher.pdf> Acesso em 21 de abril 2016.

BRASIL. Projeto de Lei $\mathbf{n}^{\mathbf{0}}$ 4559. Brasília, DF: Presidência da República, 2004b. Disponível em<http://www.camara.gov.br/proposicoesWeb/prop_mostrarintegra? codteor=256085\&filena

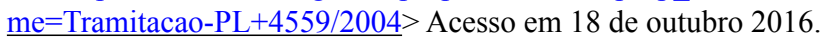

BRASIL. Lei 11.340/2006. Brasília, DF: Presidência da República, 2006. Disponível em $<$ http://www.planalto.gov.br/ccivil 03/ ato2004-2006/2006/lei/111340.htm $>$ Acesso em 29 de agosto 2016.

BRASIL. Política Nacional de Enfrentamento à Violência contra Mulheres. Secretaria Especial de Políticas para as Mulheres. Brasília, DF: Presidência da República, 2011. Disponível em $<$ http://www.spm.gov.br/sobre/publicacoes/publicacoes/2011/politica-nacional $>$ Acesso em 21 de abril 2016.

BRAZÃO, A.; OLIVEIRA, G. C. de. (Orgs.). Violência contra as mulheres: uma história contada em décadas de lutas. Brasília, DF: CFEMEA: MDG3 Fund., 2010.

CHAUÍ, M. Participando do debate sobre mulher e violência. In: CHAUÍ, M.; CARDOSO, R.; PAOLI, M. C. (Orgs.). Perspectivas Antropológicas da Mulher. Rio de Janeiro: Zahar, 1985. p. 25-62.

DANTAS-BERGER, S. M.; GIFFIN, K. A violência nas relações de conjugalidade: invisibilidade e banalização da violência sexual? Caderno de Saúde Pública, Rio de Janeiro, v. 21, n. 2 , p. $417-425,2005$.

GREIG, A. Political connections: men, gender and violence, INSTRAW-Working Paper Series on Men's Roles and Responsibilities in Ending Gender Based Violence (Working Paper, 1), 2001. Disponível em <http://menengage.org/wp-content/uploads/2014/06/Political Connections_- Men_Gender_and_Violence.pdf> Acesso em 19 de outubro 2016. 
GUIMARÃES, E. A mulher portuguesa na legislação civil. Análise Social, Lisboa, v. 22, n. 92/93, 1986, p. 557-577. Disponível em: <http://analisesocial.ics.ul.pt/ documentos/1223552761S9jHG4vr3Ci53FM9.pdf> Acesso em 30 de agosto 2016.

HeISE, L.; EllSBERG, M.; GOTTEMOELlER, M. Ending Violence Against Women, Population Reports, v. 27, n. 4, p. 18, 1999. Disponível em <http://www.vawnet.org/sites/ default/files/assets/files/2016-10/PopulationReports.pdf> Acesso em 19 de outubro 2016.

KRUG, E. G.; DAHLBERG, L. L.; MERCY, J. A.; ZWI, A. B.; LOZANO, R. Relatório Mundial sobre violência e saúde (World report on violence and health). Geneva: World Health Organization, 2002. Disponível em: < $\underline{\text { http://apps.who.int/iris/ }}$ bitstream/10665/42495/1/9241545615 eng.pdf $>$ Acesso em 31 de agosto 2016.

LIMA, R. H. G. Violência doméstica: os desafios para o Setor Saúde, In: Franco, F.; Ribeiro, P. M. C. M.; S. Gryner, S. (Orgs.). A violência começa quando a palavra perde o valor. Rio de Janeiro: Núcleo de Atenção à Violência (NAV), 2004, p. 29-38.

LIMA, D. C.; BUCHELE, F. Revisão crítica sobre o atendimento a homens autores de violência doméstica e familiar contra as mulheres. Physis, Rio de Janeiro, v. 21, n. 2, p. 721-743, 2011.

LIMA, D. C.; BUCHELE, F.; CLÍMACO, D. de A. Homens, Gênero e Violência Contra a Mulher. Saúde e Sociedade, São Paulo, v. 17, n. 2, p. 69-81, 2008.

MANITA, C. A intervenção em agressores no contexto da violência doméstica em Portugal. Lisboa: SerSilito - Maia, 2005.

MEDRADO, B.; MELLO, R. P. Posicionamentos críticos e éticos sobre a violência contra as mulheres. Psicologia \& Sociedade, Porto Alegre, v. 20, n.spe, p. 78-86, 2008. Disponível em < http://www.scielo.br/pdf/psoc/v20nspe/v20nspea11.pdf $>$ Acesso em 30 de agosto 2016.

PORTUGAL. Diário da República, 1. ${ }^{\text {a }}$ série - N. ${ }^{\circ} 243$ - 17 de Dezembro de 2010. Resolução do Conselho de Ministros n. ${ }^{\mathbf{1}} \mathbf{1 0 0 / 2 0 1 0}$ - IV Plano Nacional Contra Violência Doméstica, 2010 .

PORTUGAL. Diário da República, 1. ${ }^{\mathrm{a}}$ série - N. ${ }^{\circ} 253$ - 31 de dezembro de 2013. Resolução do Conselho de Ministros n. ${ }^{\circ}$ 102/2013 - V Plano Nacional de Prevenção e Combate à Violência Doméstica e de Género, 2013.

TURINETTO; A. Q.; VICENTE; P. C. Hombres maltratadores: tratamiento psicológico de agressores. Madrid: Grupo 5, 2008

RIBEIRO, P. M. C. M. Lidando com violência doméstica. In: FRANCO, F.; RIBEIRO, P. M.; GRYNER, S. (Orgs.). A violência começa quando a palavra perde o valor. Rio de Janeiro: Núcleo de Atenção à Violência (NAV), 2004, p. 11-16.

SAFFIOTI, H. Gênero, patriarcado e violência. São Paulo: Fundação Perseu Abramo, 2004.

TONELI, M. J.F.; LAGO, M.C. de S.; BEIRAS, A.; CLÍMACO, D. deA.(Orgs.). Atendimento a homens autores de violência contra mulheres: experiências latino americanas. Florianópolis: UFSC/CFH/NUPPE, 2010. 
Submissão em: 12/06/2016

Revisão em: 23/08/2016

Aceite em: 03/02/2017

Maria Juracy F. Toneli é psicóloga; pós-doutora em Psicologia Social pela Universidade Federal de Minas Gerais (UFMG) e Universidade do Minho/ Portugal; doutora em Psicologia Escolar e do Desenvolvimento Humano pela Universidade de São Paulo (USP). Professora Titular do Departamento de Psicologia e do Programa de Pós-Graduação em Psicologia da Universidade Federal de Santa Catarina.

Endereço: Universidade Federal de Santa Catarina Campus Universitário Reitor João David Ferreira Lima, Trindade. Florianópolis/SC, Brasil. CEP 88040-900. E-mail: juracy.toneli@gmail.com

Adriano Beiras é psicólogo; pós-doutor em Psicologia Social pela Universidad de Granada (UGr)/ University of Brighton e Universidade Federal de Santa Catariana (UFSC); doutor europeu em Psicologia Social pela Universidade Autônoma de Barcelona (UAB). Professor Adjunto do Departamento de Psicologia e do Programa de Pós-Graduação em Psicologia da Universidade Federal de Santa Catarina (UFSC).

Grupo de Pesquisa Margens (Modos de Vida, Família e Relações de Gênero) Departamento de Psicologia / Centro de Filosofia e Ciências Humanas

E-mail: adrianobe@gmail.com

Juliana Ried é psicóloga; mestre em Psicologia pela Universidade Federal de Santa Catarina (UFSC); especialista em terapia familiar sistêmica pós-moderna (Instituto Movimento). E-mail: juliried@yahoo.com.br 